\title{
Aligning Strategy with Sustainable Development Goals (SDGs): Process Scoping Diagram for Entrepreneurial Higher Education Institutions (HEIs)
}

\author{
Elena Fleacă ${ }^{1, *}$, Bogdan Fleacă ${ }^{1}$ and Sanda Maiduc ${ }^{2}$ \\ 1 Department of Entrepreneurship and Management, Faculty of Entrepreneurship, Business Engineering and \\ Management, University Politehnica of Bucharest, Bucharest 060042, Romania; bogdan.fleaca@upb.ro \\ 2 Department of Management for Scientific Research Activities, University Politehnica of Bucharest, \\ Bucharest 060042, Romania; sanda.maiduc@upb.ro \\ * Correspondence: elena.fleaca@upb.ro; Tel.: +40-74-486-9274
}

Received: 16 March 2018; Accepted: 29 March 2018; Published: 30 March 2018

\begin{abstract}
Seeing that the prosperity of people and society is possible with the aid of sustained and inclusive economic growth of all countries and regions, the sustainable development of our world has gained the particular attention of a wide range of decisional factors; civil society, the business sector, and the scientific community. Education has a decisive impact on changes in the way that societies are coping with national, regional, and global challenges and opportunities brought by sustainable development. The paper addressed the lack of capacity of higher education institutions (HEIs) to integrate the principles and practices of sustainable development into all aspects of education and learning, which hampers the capability to act as an entrepreneurial university. Embarking on the path of sustainable development goals (SDGs) requires HEI to design, launch, implement, and customize specific processes architecture to govern the advance of the sustainability approach. The authors applied the process scoping diagram to capture and conceptualize the educational model needed to guide the HEI through the process of change in its daily operations. The SIPOC method (Supplier, Input, Process, Output, Customer) was applied and with the aid of Visio software tool, the processes relationships were articulated and embedded in the educational model of HEI. Finally, the authors shared their views on the scalability of the model, which may be customized and harmonized in accordance with different HEI's circumstances and priorities.
\end{abstract}

Keywords: entrepreneurial sustainability strategy; entrepreneurship and management; business process management and improvements; innovation in higher education; sustainable organizational performance; sustainable business models

\section{Introduction}

Over the last decades, sustainable development has gained the particular attention of a wide range of decisional factors. These decisional factors reinforce that the prosperity of people and society is possible with the aid of continual, inclusive, and sustainable economic growth of all countries and regions.

The high-level stakeholders' commitment to sustainable development was exhaustively defined in the 2030 Agenda for Sustainable Development issued by the United Nations. The fundamental changes were clearly captured and defined within 17 universal sustainable development goals (SDGs) and related targets, balancing all facets of sustainable development such as economic, environmental, and social concerns [1].

The role of the education system in sustainable development was revealed by the universal goal of providing inclusive and equitable education and lifelong learning opportunities for all people (SDG 4), 
with assigned 2030 targets and indicators such as participation rate in different education levels and forms, extent to which citizenship education and sustainable education are mainstreamed at all levels in curricula, teacher education, student assessment, and also a proportion of youth and adults with relevant skills in information technology and communication (ITC) and entrepreneurship, etc. [2]. Based on national circumstances and priorities, each country is responsible for committed educational models needed to achieve sustainable development. These acknowledged the decisive impact of the educational environment to the fundamental changes in the way that societies are coping with national, regional, and global challenges and opportunities.

The commitment to sustainable development was also acknowledged by the European Union (EU) with a straightforward focus on three priorities for higher education systems seen as the foundation of fair, open and democratic societies and of sustained growth and employment: (i) quality and relevance of skills formation; (ii) more visible and comparable skills and qualifications, and advancement of skills intelligence; and (iii) informed career choices [3]. To better underpin higher education in society, the EU renewed its agenda for education and refined further priorities in terms of promoting excellence in skills development, building inclusive and connected higher education systems, ensuring HEIs contribution to innovation, and supporting effective and efficient HE systems [4].

To guide the progress on SDGs achievement, the United Nations Human Rights Council adopted the United Nations Guiding Principles on Business and Human Rights (UNGPs) — the most comprehensive global framework to address the business impacts on human rights. Based on a set of 10 guiding principles laying out the main idea of the state duty to protect, the framework addressed corporate social responsibility by supporting and encouraging responsible business practices, and consequently, the sustainable development of the wider society [5].

The positive impact businesses may have on the social and economic development is also acknowledged by the linkage of entrepreneurship in the majority of sustainable developments goals (SDGs) among which ensuring inclusive and equitable quality education and promoting lifelong learning opportunities for all (SDG 4) and inclusive and sustainable economic growth, full and productive employment and decent work for all (SDG 8). Social entrepreneurship is also emphasized as a key concept to engage business and civil society in addressing emerging social challenges and reducing inequalities and enhancing social cohesion [6].

In response to these sustainability challenges, the EU stated its view by defining the concept of corporate social responsibility as the responsibility of enterprises on their impacts on society, regardless of size, type, and operating industry. With a comprehensive approach of sustainable responsibility, decisional bodies have underpinned the targets of Europe 2020 strategy for smart, sustainable and inclusive growth, including 75\% employment rate, 3\% of the EU's Gross Domestic Products investment in research and development, reduced greenhouse emissions, diminished early school leavers below $10 \%$, a min share of $40 \%$ of people with higher education attainment, and poverty and social exclusion reduction by $25 \%[7,8]$.

Useful research devoted their attention to critical issues that may hamper business practices, job creation, and economic growth, and therefore, the EU 2020 targets and sustainable development of societies. In this regard, at the EU level, the main harmful issues in doing business are seen as tax rates by $63 \%$ of companies, fast-changing legislation and policies $(61 \%)$, the complexity of administrative procedures $(60 \%)$, and corruption which were mentioned by $38 \%$ of companies. Also, $67 \%$ of EU companies perceived corruption as being widespread in their country, being a real problem mainly for smaller companies (38\% of companies with 1-9 employees versus $15 \%$ of companies with 250 or more employees) [9].

From the EU citizens' viewpoint, the overall patterns of tolerance to corruption vary significantly between countries (e.g., Hungary with $35 \%$ of respondents thinking corruption as being unacceptable, followed by Croatia with $45 \%$, and Finland and Portugal both with $84 \%$ ). As regard to respondents' perception about the spread of corruption, $68 \%$ of EU respondents perceived corruption as being widespread within their own country, and just over a quarter (26\%) said that it is 'very widespread'. 
Almost a quarter of EU citizens (25\%) mentioned that they were personally affected by corruption in their daily lives, with significant differences between countries e.g., in Romania $68 \%$ of respondents mentioned to be affected by corruption, in Cyprus almost a half (50\%), and Denmark with only $4 \%$ of respondents [10].

The corruption issues are of utmost importance especially for former communist countries, and not only, which are struggling with different forms of corruption spread out through all activities and sectors. For example, current studies on Romania country noted that $93 \%$ of citizens viewed corruption as an important problem, $79 \%$ as very important and a further $14 \%$ as fairly important. All of the self-employed respondents and $95 \%$ of employees said corruption as an important problem while $91 \%$ of manual workers gave the same answer. Moreover, when asking to compare the current situation with 10 years previously, at the point when Romania become the member of EU, $45 \%$ of respondents marked that things had got worse, $10 \%$ declared that things were slightly worse and over $35 \%$ saying that they were much worse [11].

In the same light, corruption issues in the Romanian public sector are among the top challenges for business sectors, hindering economic growth. The main obstacles to doing business in Romania are identified as corruption by $85 \%$ of businesses versus EU average of $37 \%$, and $70 \%$ of businesses think that the only way to succeed in business is to have political connections, compared to EU average of $42 \%$ [12]. To reduce the corruption prevalence and to encourage public bodies to allocate resources to anti-corruption work, Romania has required to design and implement a corruption prevention policy especially in key sectors as education, health and local authorities. Unfortunately, the progress towards the completion of anti-corruption strategy is in early stage since the report on progress of Romania under the co-operation and verification mechanism stated the need for concrete indications that corruption prevention is taking root and tangible political support is devoted to demonstrating the progress [13].

As far as Romania country, these figures acknowledge the negative impact of different forms of corruptions on economic growth, creating business uncertainty, undermining the trust in governments and public institutions, damaging democracy and slowing the entire process of SDGs accomplishment, as defined in the 2030 Agenda for Sustainable Development.

Looking at the role of education, especially higher education, on the progress of society through its mission of fostering sustainable development of societies by respect for human rights, anti-corruption and citizenships, innovation and entrepreneurship, the authors addressed the lack of HE institutional capacity to integrate these principles and practices into all aspects of education and learning. The scope of research problem was bounded on the capability of HEI to act as entrepreneurial university by combining the scope of its responsibility (i.e., social, environmental, and economic) within the value chain (research and development, teaching and learning, knowledge exchange and technological transfer) through a practical and effective mechanism needed to align the strategy with envisaged sustainable development goals (SDGs).

\section{Methods}

The path of sustainable development requires decisional factors from each HEI not only to assume the SDGs but also to design, launch, implement, and customize specific processes architecture to govern the advance of sustainability approach. In this regard, the research objectives were: (i) secondary research on international literature to analyze relevant advancements in the area of sustainable development coupled with business and educational process models (points 2.1 and 2.2); and (ii) applying the process scoping diagram to conceptualize the educational model needed to guide the HEI through the process of change to embrace sustainability into organizational culture and daily operations (point 2.3). For the purpose of modeling endeavor, the authors applied the SIPOC method (Supplier, Input, Process, Output, Customer) with Visio software tool to articulate processes relationships embedded in the educational model of HEI. 


\subsection{Sustainable Development and Business Implications}

Multiple studies were devoted to investigating the institutionalization of sustainable development approach in organizational context. The scholars emphasized the main role of the management board in ensuring the convergence between insider and outsider facets of the organizational system, having a key role in embedding the sustainable development into the business culture [14].

In the light of increasing importance of sustainability in the regional context, other research focused on the internal side of social responsibility of organization and set indicators to increase responsible human practices toward effective implementation of sustainability strategy: responsible human resources practices; organizational culture of responsibility; social projects promotion; significant compensation policies and employees' quality of life [15].

Other attempts proposed different conceptual frameworks to integrate corporate social responsibility, human resource development, and lifelong learning activities as educational engagements for mutual benefit of company and employees. These offered guidelines for integrating and designing specific measures and functions of human development and corporate social responsibility into the company environment [16].

To further question the challenge of sustainable strategy, the research diagnosed key factors as leadership, strategy, employees, corporate values, resources, tools, and processes to support the implementation of strategy. As implementation is a very complex endeavor, the success consists of holistic comprehension of these factors and their reciprocal influences within the specific circumstance of the company [17].

Others paid their attention to decision-making methods by analyzing and quantifying the magnitude of changes needed to increase the performance of the organization, based on financial perspectives. By knowing the importance rank of different perspectives (e.g., financial, customer, internal business processes, learning and growth) and related key performance indicators (e.g., cost structure, reduction of cost, user satisfaction, cost per use, performance, productivity, delays, quality, budgeting, etc.), the strategic line of the company may establish priorities and design the process-based model to improve productivity and cost performance $[18,19]$.

However, one of the most comprehensive approaches is envisaged by the internationally recognized standard ISO 26000:2010 that foreseen key subjects to integrate economic, environmental and social considerations into existing organizational systems, practices and processes. Based on a common understanding in the field of social responsibility, the standard guides the organization in its pursuit of implementing accountability principles, transparency, ethical behavior, respect for stakeholders' interests and respect for the rule of law, with the aid of organizational governance [20].

To further root the implementation of sustainable development principles into companies' strategies and operations, the Global Reporting Initiative (GRI) championed a common language that supports the process of identifying the impacts of organizations on economy, environment, and society, and disclosing them in accordance with a set of principles globally accepted as standards. These enable organizations to communicate the progress in achieving the committed SDGs, helping them to incorporate SDGs reporting into their existing processes. Information on organizational performance is articulated with respect to economic, environmental, and social conditions at the local, regional, or global level, depending on the size, type, sector, or geographic location [21]. In fact, the communication on SDGs achievement is seen as an overarching framework for shaping, steering, communicating and reporting the progress toward SDGs, bringing valuable benefits for all stakeholders in terms of increased value creation through future business opportunities, enhanced economic value based on an improved use of resources, strengthened stakeholders' relations through empowered trust, fair and opened business sector with rule-based market, financial transparency, and well-governed and non-corrupt institutions [22,23]. 


\subsection{Sustainable Development and Educational Implications}

The growing importance of education in sustainable development of societies is acknowledged by the UNESCO strategy for education which set three strategic objectives in terms of: (i) developing educational systems to foster quality and inclusive lifelong learning for all; (ii) empowering learners to be creative and responsible global citizens; and (iii) advancing education for all. Also, through explicitly recognizing the major role of education to attainment of SDGs, it has been proposed a cross-cutting framework to guide the educational organizations in establishing learning objectives relevant to SDGs and in implementing learning for SDGs through policies, strategies, and programs, curricula and textbooks, teacher educations, and assessing learning outcomes [24,25].

These raised the question of critical sustainability issues in education and the commitment of decisional factors towards incorporating SDGs into HEIs strategies and processes. However, current studies emphasized that sustainability concerns and reporting in HEIs are still in their early stages. The HEIs need to consider sustainability reporting as a dynamic tool to plan sustainability changes, and not just as a communication activity, requiring thus a systematic and continuous evaluation of economic, environmental, and social concerns. Notably, the absence of external stakeholders' engagement process, the lack of inclusion of material impacts in reports, and the lack of institutionalization are mentioned as main factors hindering the adoption of a systematic reporting process on HEI's sustainability [26].

The adoption of process management approaches and methodologies in the world of education, especially in HEIs, are slightly studied and analyzed. There is some useful research in the field of vocational education and training stressing the key role of sustainability assessment framework toward improving the impact on economic, environmental, and social dimensions. The sustainability areas (e.g., institutional capacity and management, environmental responsibility, economic performance, social responsibility, training provision) have been appreciated to improve sustainable culture inside the organization, offering valuable information for the adoption of sustainable development strategy [27]. Other emphases were focused on applying the business process modeling methodology in HEI and providing a framework for higher education processes. With a narrow boundary on teaching and learning process evaluation, the model promoted the benefits for competitive universities to manage internal processes similar with enterprises business processes [28].

Also, the toughest sustainability issues in HEIs are addressed by thoroughly organizational changes which need to incorporate sustainable development strategy into daily operations. Previous findings mentioned the need of entrepreneurial universities to conceptualize and use innovative educational models to embed international strategy within educational processes from value chain and also articulate those processes in charge with effectively managing stakeholders' relationship [29,30].

By summing up, entrepreneurial HEIs create value for all stakeholders ensuring long-term competitive advantage by capturing all facets of sustainable development in terms of social, environmental, and economic concerns. This implies each university to design, implement, monitor and further develop comprehensive mechanisms based on process management approach to stimulate responsible business conduct for innovation and entrepreneurial development of people and wider society.

\subsection{Process Approach and Sustainability Issues in Higher Education}

The process approach is one of the most important ways to understand the business and/or organization as a system by which internal and external components are connected and interrelated. The system thinking stressed the concept of process models by which the organization performance is ultimately determined by the synergetic effect of three levels of performance such as job level, process level, and organizational level. By this way, the perspectives of goals and measurements, designing and implementing organizational issues are successfully integrated by the management system [31]. 
Multiple studies captured, analyzed and developed different models which stress the relationship between organization performance, business processes and management approach. In this regard, scholars proposed aligning daily work practices with business process descriptions and improvements by involving stakeholders' through agile business process management methodology through three phases: process discovery; process supervision; process assessment and improvement. The phases are in conformance with the management cycle of plan-do-check-act and consider the organization's dimensions and business processes complexity. Also, it was envisaged a meta-model supporting the agile version of business processes and the alignment of actual work practices for process improvement [32,33].

Although process-based methodology is well-known and studied, the organizations are still struggling with a high resilience toward improvements changes, the lack of managerial support in adopting process improvement, and also with the shortage of specialists in process analysis, design, and implementation [34]. In addition, the social dimension of process thinking was analyzed to promote collaborative meta-models for executing processes through knowledge sharing and collective decisions [35]. Key process parameters were analyzed to map the real value stream in complex business processes such as economic value-added and business process value-added calculated on the basis of several production value-added index [36].

By taking advantages of process approach and in response to critical issues in higher education, the authors attempted to integrate the principles and practices of sustainable development into all aspects of education, and model the process of aligning the sustainability strategy with SDGs in the case of HEI. This alignment strategy with SDGs would be of great help, especially for those HEIs which are striving to fulfill their missions in countries struggling with corruption and shortcomings in economic and social systems.

The methodology applied was based on the well-known SIPOC (Supplier, Input, Process, Output, and Customer) method from Six Sigma approach which helps scope the work to understand the process for aligning HEI's strategy with SDGs [37].

Regardless of detail level, a process describes a flow of activities that transform inputs elements in outputs elements, and SIPOC enables the graphical representations of the processes, interrelationships, and sequence of steps $[38,39]$. In this way, the scope of work is integrated, enabling further analysis of process variations and related metrics for improvements, cycle time, and improvements metric performance, to create well process governance. Table 1 designates the core components of SIPOC method and main descriptors.

Table 1. Supplier, Input, Process, Output, Customer (SIPOC) components.

\begin{tabular}{cl}
\hline Name of Component & \multicolumn{1}{c}{ Descriptors } \\
\hline Supplier & The process and/or other entity providing what is necessary for the process working flow \\
Input & Different demands (information and/or materials) triggering the process execution \\
Process & High-level transformation flow performed in response to the inputs \\
Output & The result (product and/or service and/or information) of the transformation flow \\
Customer & The process and/or other entity using the results for next steps in the process \\
\hline
\end{tabular}

The process scoping diagram with SIPOC components usually takes place during improvements projects to provide an outside-in approach on organizational flow, aiming to streamline the processes from the customers' views. It requires two steps as follows:

- I. Analyzing and articulating the high level process groups considering the whole scope of HEI's responsibility as an organization and educational institution [40]. In this regard, Table 2 depicts the cross-functional structure of HEI processes needed to ensure a clear line of sight between the mission, overall objectives and related governance. 
Table 2. The cross-functional structure of higher education institutions (HEI) processes.

\begin{tabular}{ll}
\hline Process Category & Process Group Sub-Category \\
\hline & CP 1.1. Research, development, and innovation (R\&D\&I) \\
1. Core/value chain Processes Group (CP) & CP 1.2. Academic and teaching operations \\
& CP 1.3. Dissemination of scientific results and \\
& technological transfer to market \\
\hline & SP 2.1. Facility management \\
& SP 2.2. Public relations \\
2. Support and administrative Processes Group (SP) & SP 2.3. Financial and accounting \\
& SP 2.4. Information technology \\
& SP 2.5. Students services and operations \\
& SP 2.6. Human capital development \\
\hline & MP 3.1. Planning value chain and operations \\
& MP 3.2. Monitor and control value chain operations \\
3. Management Processes Group (MP) & MP 3.3. Monitor and control support operations \\
& MP 3.4. Quality assurance and improvement \\
\hline
\end{tabular}

The cross-functional structure of HEI covers three process categories which stand for:

1. Core/value chain Processes Group (CP) enabling the advancement toward sustainable development, grounded on three groups of processes: CP 1.1. Research, development and innovation (R\&D\&I) - responsible for knowledge creation as a response to the wider challenges of sustained growth; CP 1.2. Academic and teaching operations-in charge of development of relevant and high-quality skills and key competences to foster employability and personal life; CP 1.3. Dissemination of scientific results and technological transfer to market - with a view to maximize the transfer of innovative results to the wider society.

2. Support and administrative Processes Group (SP) ensuring effective and sustainable implementation of value chain processes of HEI, with six groups of processes: SP 2.1. Facility management-manages the campus infrastructure, facility housekeeping, and maintenance activities; SP 2.2. Public relations-responsible for communication network with HEI's stakeholders and the wider community; SP 2.3. Financial and accounting-manages financial resources with procedures for general accounting and reporting, payroll system, expense reimbursements, treasury operations, etc.; SP 2.4. Information technology-in charge with ITC network, maintaining and developing a virtual educational platform for innovative teaching activities; SP 2.5. Students services and operations-guides students relationships with the university as enrollment, fees, exams records, grants, and other activities; SP 2.6. Human capital development-legal provisions and different procedures to hire, appraise, reward and promote teaching and administrative staff.

3. Management Processes Group (MP) enabling functioning of HEI as an integrated system of social, environmental and economic responsibilities grounded on four groups of processes: MP 3.1. Planning value chain and operations-in charge with yearly planning of academic activities and related support operations; MP 3.2. Monitor and control value chain operations-collects performance information and adopt corrective decisions on value chain activities; MP 3.3. Monitor and control support operations-collects performance information and adopts corrective decisions on administrative sides; MP 3.4. Quality assurance and improvement-ensures the control improvement loops in HEI based on procedures for internal performance evaluation and measurements, being ultimately accountable for engaging HEI on the road of sustainable development.

- II. Designing the SIPOC diagram, a high-level map of processes, to align the HEI strategy with SDGs, to document high-level steps that bound the process, the information being used, 
internal and external stakeholders' interrelationships, inputs used in the process steps and outputs produced.

The process scope diagram based on SIPOC method was developed taking into consideration the United Nation Global Compact Management model comprising a high-level guide for organizations committed to SDGs, being articulated and customized in the complex case of HEI [22].

\section{Results and Discussion}

The key results of conceptual design are represented by four phases which ensure coherence and synergies among different categories as value chain, administrative, and management processes. Also, the authors designated the interactions with the cross-functional structure of HEI as presented in:

- $\quad$ Phase 1. Design alignment strategy of HEI with SDGs, Figure 1.

- $\quad$ Phase 2. Direct and manage alignment strategy of HEI with SDGs, Figure 2.

- $\quad$ Phase 3. Monitor and control the implementation of strategy, Figure 3.

- Phase 4. Report and communicate the progress of HEI against SDGs, Figure 4.

Phase 1. Design alignment strategy of HEI with SDGs provides the workflow to plan the alignment strategy of HEI with SDGs, as described below.

\section{- Inputs}

The starting point of the flow is ensured by the leadership commitment of HEI to support SDGs in a transparently way, being a key output of the planning processes group. In order to define the HEI priorities with respect to social, environmental, and economic concerns, the process architect is required to carefully consider the HEI governance model which sets the management architecture as organization and school, and also the committed SDGs. This information is delivered by the process MP 3.1. Planning value chain and operations from the Management Process Group (Table 2).

In addition, critical sustainability issues in the higher education should be considered for evaluation through the examination of international and county-specific rules and provisions on human rights and labor, environment, and anti-corruption. Also, the process architect should take advantage of industry-specific database as GRI standard and UN global compact, as described earlier. The quality assurance and improvement process (MP 3.4.) is in charge of delivering this documented information.

\section{- Process activities}

The flow of activities starts with defining and assessing HEI scope of responsibility (A1.1) followed by setting the SDGs and related targets (A1.2) based on useful information provided by the inputs. The flow goes on with defining the action plan for achieving related KPIs for each sustainability issue (A1.3) and with designing the reporting system (A1.4) to be put in place to collect data and information for communication on SDGs progress (A1.5). The alignment strategy of HEI with embedded SDGs is designed (A1.6) and, after formal approval, the strategy needs to be communicated to the community (A1.7). The scope of work is permanently evaluated through a set of analysis, evaluation and review activities as preventive actions to reduce the variation of the quality of the activities.

\section{- Outputs}

The impact \& priorities map coupled with baseline framework of HEI's responsibilities define the unique operating context related to its social responsibility (e.g., human rights, labor health and safety, personal development and well-being of staff, students and graduates, social responsible behavior), environmental responsibility (e.g., energy, climate change, waste and pollution, and other relevant environmental issue), and economic responsibility (e.g., financial transparency and sustainability, anti-corruption, community development, internationalization, and governance).

The SDGs and related key performance indicators (KPIs) are established based on the assessment of risks and opportunities in financial and non-financial terms, as well as the impact on these critical 
issues on human rights, labor, environment, and anti-corruption. In response to previous findings, the HEI needs to establish sets of indicators and metrics for each category (e.g., student admissions, non-discrimination, safe and study conditions, freedom of association for students and staff, hiring and advancement practices, labor policies, environmental programs and policies; green purchasing practices; contracting policies; plagiarism in education and research, and intellectual property issues) [22-24]. All information developed during the implementation of activities will feed the HEI strategy with embedded SDGs which need to become public after a decision point for endorsement purpose.

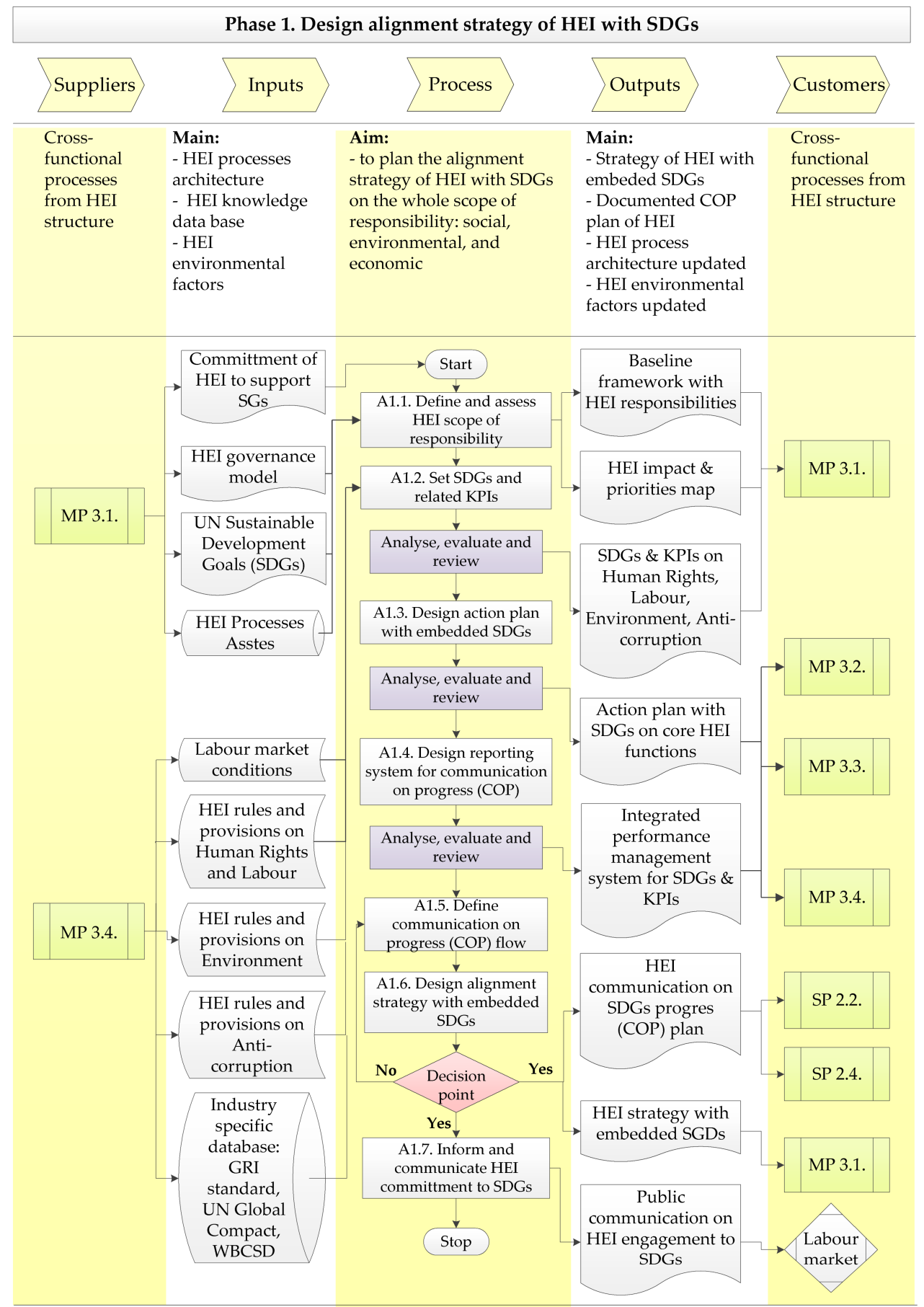

Figure 1. Design alignment strategy of HEI with of sustainable development goals (SDGs) (phase 1). 


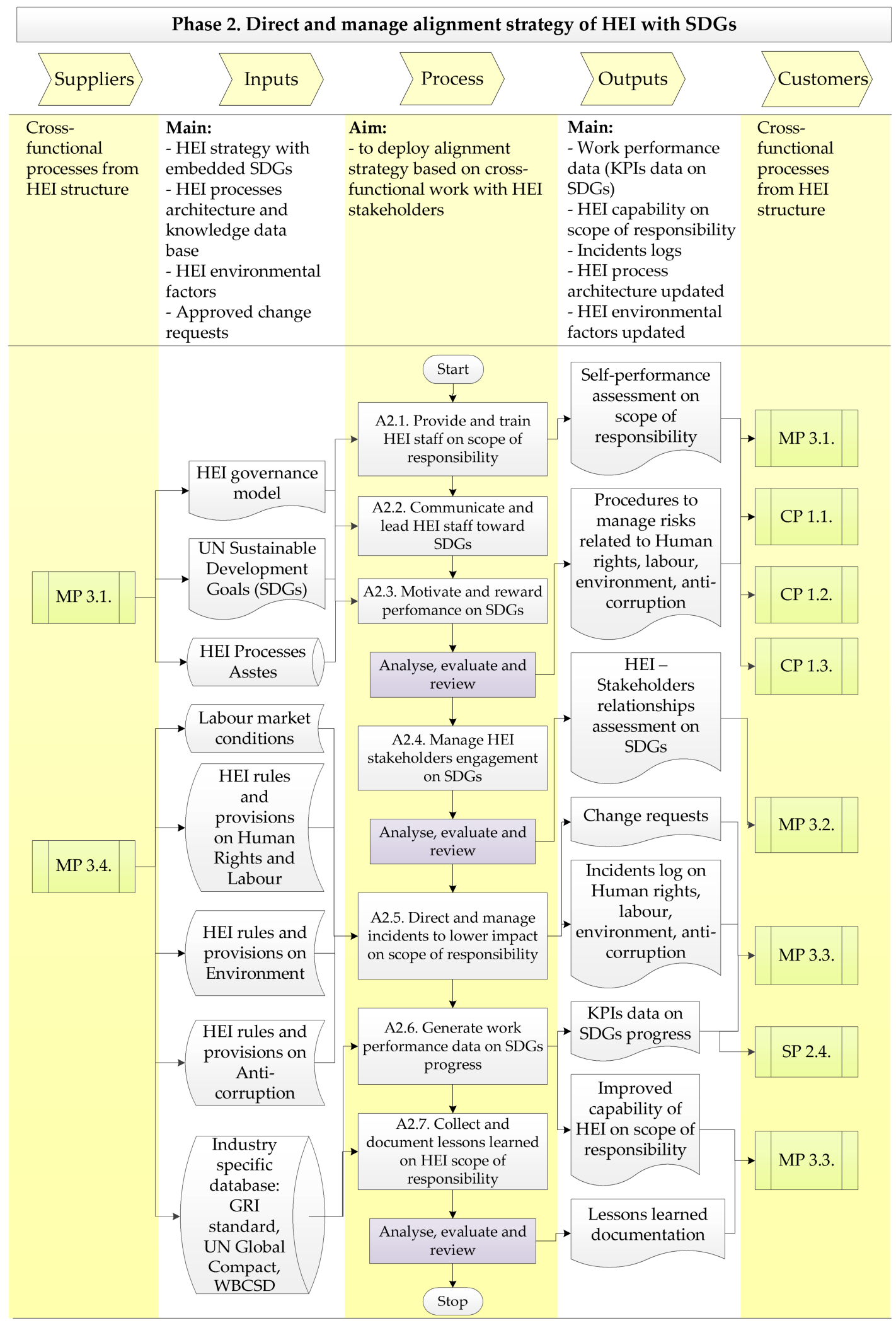

Figure 2. Direct and manage alignment strategy of HEI with SDGs (phase 2). 


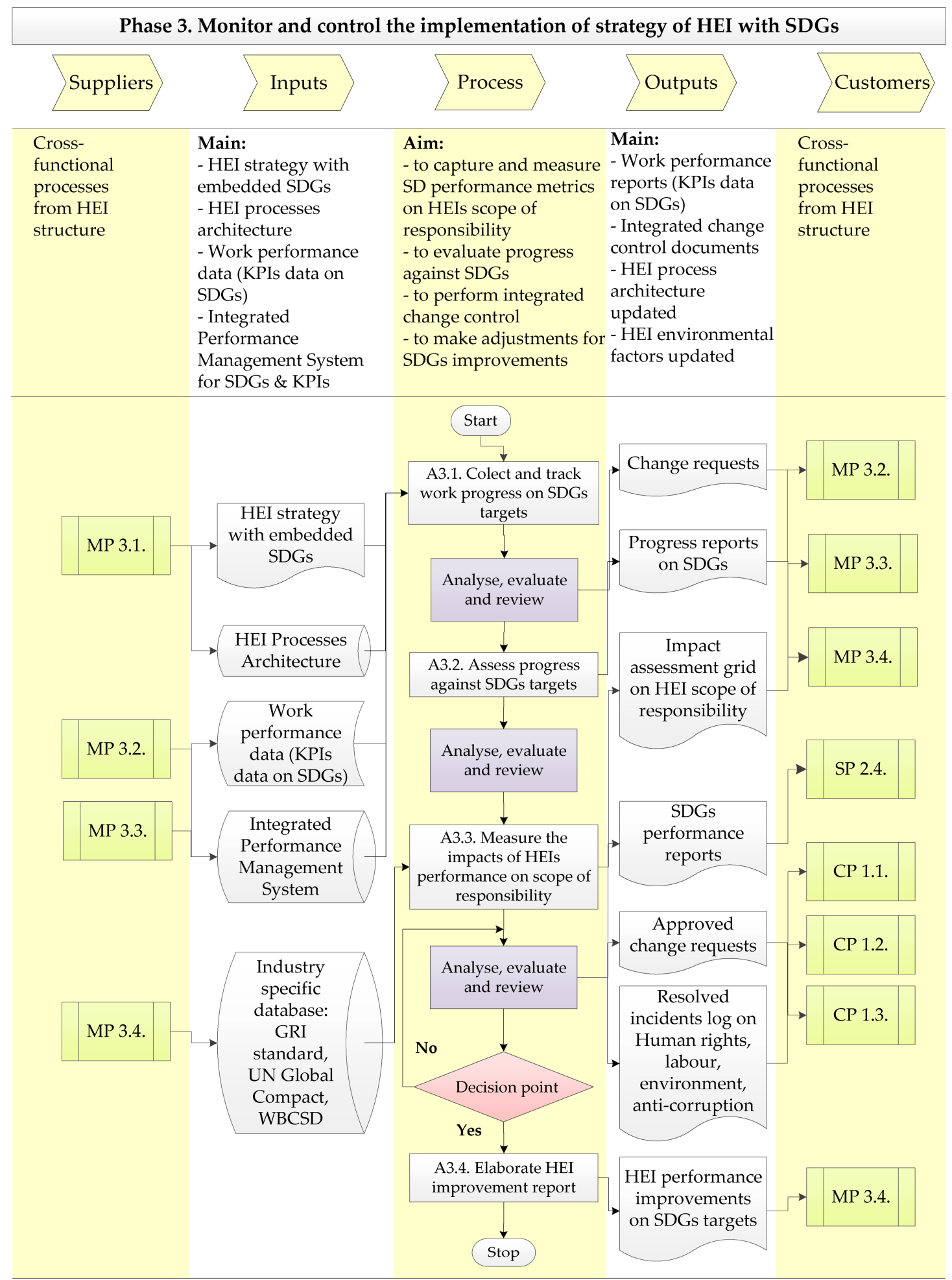

Figure 3. Monitor and control the implementation of strategy (phase 3). 
Phase 4. Report and communicate the progress of HEI against SDGs

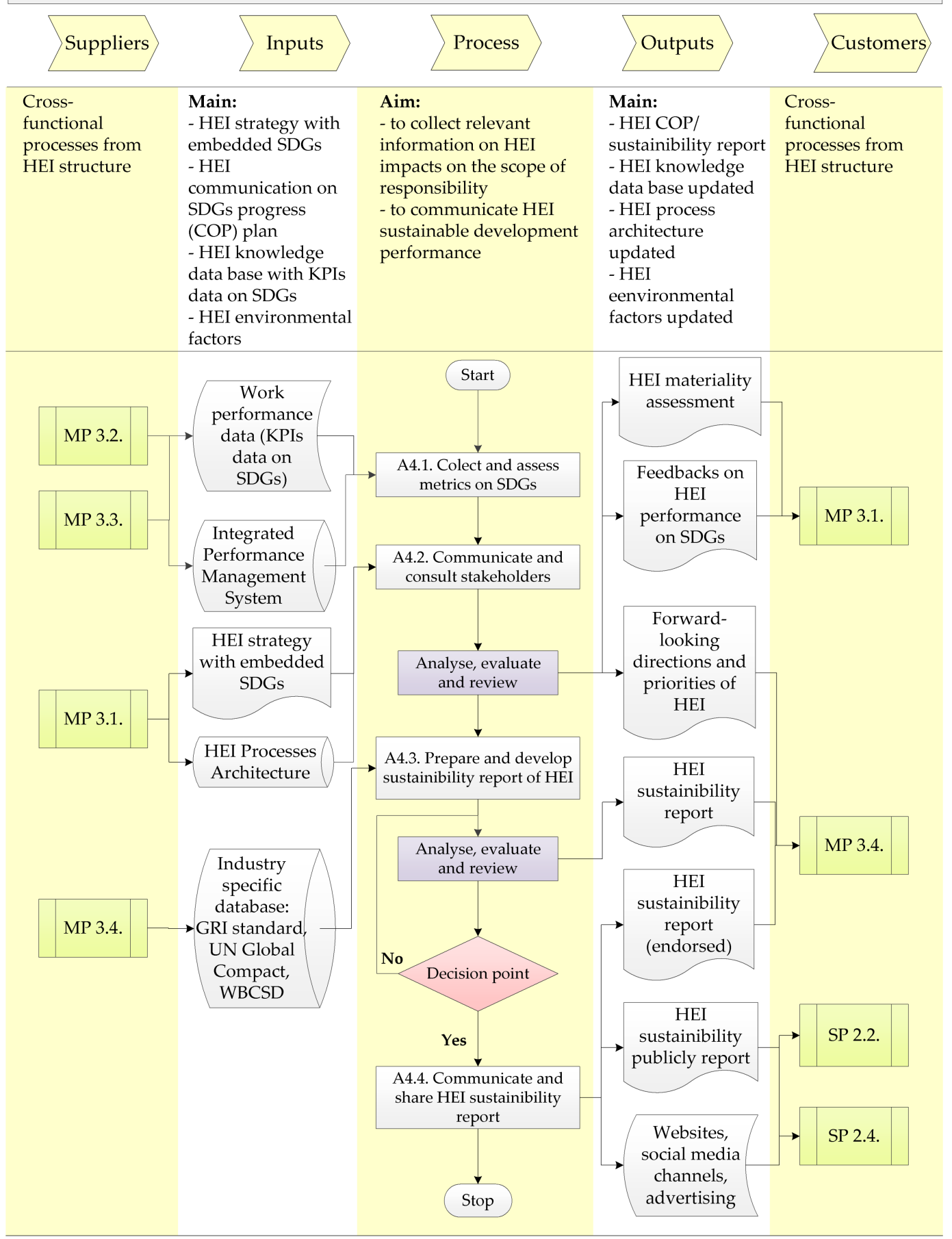

Figure 4. Report and communicate the progress of HEI against SDGs (phase 4).

These outputs feed processes from the cross-functional map of HEI as: MP 3.1. Planning value chain and operations, MP 3.2. Monitor and control value chain operations, MP 3.3. Monitor and control support operations, SP 2.2. Public relations, and SP 2.4. Information technology.

Phase 2. Direct and manage alignment strategy of HEI with SDGs provides the scope of work needed to implement the strategy, as described below. 


\section{- Inputs}

The phase uses main outputs of the phase 1 and considers the approved change requests issued while work is performed, and also relevant factors from HEI which may hamper the implementation of alignment strategy with SDGs. The processes responsible for delivering these inputs are: MP3.1. Planning value chain and operations and MP 3.4. Quality assurance and improvement, from the Management Process Group (Table 2).

\section{- Process activities}

The phase begins with training of teaching and administrative staff (A2.1) to develop and encourage a right-aware and transparent approach in both educational and operational sides, followed by communication and leading work toward SDGs (A2.2), and motivation of performance on SDGs (A2.3) to stimulate and reward the integration of sustainability practices related to human rights, labor, environment, and anti-corruption into daily activities.

To anchor sustainability across the whole of HEI responsibility, it would be helpful to manage multi-stakeholders engagement on SDGs (A2.4) to support the development of socio-economic aspects, in addition to the traditional teaching and research sides [41]. This implies fully engagement of all partners in setting shared goals with clear governance structure, depoliticizing projects, focusing on impacts, and creating a process for shared knowledge management across the partnership. The importance of this process is fully acknowledged by the goal 17 from the 2030 Agenda for Sustainable Development [1].

The flow envisages suitable activities for managing incidents to reduce the impact on HEI scope of responsibility (A2.5), generating work performance data on SDGs progress (A2.6), and documenting lessons learned during process implementation (A2.7).

This phase ensures useful data on work performance against SDGs progress and also lessons learned with critical sustainability issues collected through reporting procedures throughout the phase 3 of monitoring and controlling. Also, the flow is permanently evaluated through dedicated activities for analysis and evaluation to diminish the variation of the quality of the outputs.

\section{- Outputs}

The main outputs are referring to work performance data on incidents (i.e., human rights, labor, environment, and anti-corruption), data on SDGs progress, and change requests issued to adjust the work in progress on SDGs accomplishment. Also, with the purpose of improving further HEI performance on SDGs, lessons learned with documented key incidents from managing activities are issued. These outputs feed processes from the cross-functional map of HEI as: CP1.1. Research \& development \& innovation, CP1.2. Academic and teaching operations, CP1.3. Dissemination of scientific results, MP 3.1. Planning value chain and operations, MP 3.2. Monitor and control value chain operations, MP 3.3. Monitor and control support operations, and SP 2.4. Information technology.

Phase 3. Monitor and control the implementation of strategy of HEIs with SDGs is mainly intended to collect performance metrics on SDGs and to assess measurements to make improvements.

- Inputs

The phase is fed by all the outputs of the phase 2 such as work performance data on KPIs, integrated performance management systems for SDGs and KPIs, and also HEI processes architecture and the approved alignment strategy with SDGs. This information is delivered by the Management Processes Group in charge with planning, monitoring and controlling, and quality assurance (i.e. MP 3.1., MP 3.2., MP 3.3. and MP 3.4.) from the cross-functional structure of HEI (Table 2).

\section{- Process activities}

This phase is characterized by a high complexity due to the need to coherently concentrate two relevant components for monitoring and controlling: final quality check of the outputs produced 
during execution (static focus) and ongoing evaluation of work (dynamic focus) related to the way of performing the work. For the purpose of quality check, the flow envisages capturing and measuring performance metrics (A3.1 and A3.2), and measuring the impact of performance on the scope of HEI's responsibility (A3.3). In addition, for ongoing evaluation of work, the flow is permanently evaluated through dedicated activities for analysis and evaluation to diminish the variation of the process itself. All these are finally integrated into the consolidated report on HEI performance on SDGs targets and indicators (A3.4).

\section{- Outputs}

The outputs consist of change requests for improvement purpose, progress and performance reports on SDGs based on the progress assessment and impact measurement. The approved change requests and the resolved incidents on human rights, labor, environment, and anti-corruption are delivered with the aid of integrated change control activities providing regularly recurring data updates. These outputs feed processes from the cross-functional map of HEI as: CP1.1. Research \& development \& innovation, CP1.2. Academic and teaching operations, CP1.3. Dissemination of scientific results, MP 3.1. Planning value chain and operations, MP 3.2. Monitor and control value chain operations, MP 3.3. Monitor and control support operations, and SP 2.4. Information technology.

Phase 4. Report and communicate the progress of HEI against SDGs is dedicated to communicate the progress (COP) and to publicly acknowledge the commitment of HEI towards SDGs.

\section{- Inputs}

The phase uses outputs from phase 2 and 3, and work performance data with KPIs on SDGs and HEI communication on progress (COP) plan. The strategy of HEI with embedded SDGs and specific processes should be also considered by the process architect. This information is delivered by the Management Processes Group in charge with planning, monitoring and controlling, and quality assurance, which has a key role in ensuring that reporting and communication processes are in line with widely accepted principles and best practices performance indicators as GRI guidelines [20,21].

\section{- Process activities}

The flow starts with collecting and assessing metrics on SDGs (A4.1), followed by engaging stakeholders (A4.2) to solicit feedback on SDGs and to get inputs on further directions. The sustainability report of HEI is prepared and developed (A4.3), and after a decision point for endorsement purpose, the report is shared and communicated to the wider community through suitable channels (A4.4). The scope of collecting, preparing and developing sustainability report of HEI is permanently evaluated through a flow of analysis, evaluation and review activities to reduce the variation of the quality of the report. The accent is mainly related to the credibility of sustainability report which requires a thoroughly focus on the completeness and accuracy of information provided, and on the relevance of success and shortcomings for judging the sustainability performance, on the whole scope of HEI responsibility.

\section{- Outputs}

The main outputs consist of the sustainability report with embedded performance on SDGs and forward-looking directions and priorities of HEI. The processes performed toward SDGs should be incorporated in the process architecture and knowledge database of HEI for further reiterations. These outputs feed processes from the cross-functional map of HEI as: MP 3.1. Planning value chain and operations, MP 3.4. Quality assurance and improvement, and SP 2.2. Public relations and SP 2.4. Information technology—for dissemination purpose to the wider public (e.g., students, faculties staff, media, employers, business community and civil society, students, government) through websites, social media channel's, and other advertising modalities.

In this way, the educational model proposed comprises all phases needed to cover the loop of sustainability commitment toward public accountability, transparency, and continuous improvement. The steps embedded in each phase integrate internationally recognized guidelines in sustainability 
commitment and reporting, and map the streamlined flow from the inception to the completion point of the planning endeavor required to align the HEI strategy toward SDGs.

The model has certain limitations given by the main focus on design and requires to be tested in different HEI settings to collect feedbacks, to adjust the inputs, outputs and process activities. Besides this, having a broad scope, the process diagram for alignment strategy of HEI with SDGs needs to be customized and harmonized with different HEI circumstance and priorities. The benefits rely on the improved capacity of those HEIs willing to have a well-governed structure, demonstrating their transparency and predictability of the value chain, administrative and management processes.

Also, the model proposed represents a consistent and effective way to reinforce institutional commitment, performance improvements, and communicating the strategy for sustainable development, especially for those HEIs having problematic features in the fight against different forms of corruptions.

\section{Conclusions}

Sustainability conceptualization stresses the comprehensive nature of education for peace and sustainable development, thus acknowledging the growing need of educational agents to empower action to make positive contributions to SDGs.

By taking into consideration the cross-functional structure of HEI processes, which ensures a clear line of sight between the mission, overall objectives and institutional governance, the authors applied the SIPOC method (Supplier, Input, Process, Output, Customer) and used the Visio software tool to articulate processes relationships embedded in the educational model leading to the alignment of HEI strategy with SDGs.

Although there is no one-size-fits-all approach, the process scoping diagram embraces all the management loops needed to design, implement, monitor and control, and report the sustainability effort of any HEI toward SDGs accomplishment. The limitations of the model rely on answering the question related to what should be done with respect to sustainability effort. Further steps require assigning human and technical resources needed to implement the educational model through an institutional re-engineering project. This improvement approach enables the identification of internal sources of variations related to the metrics assigned to generate improvement opportunities and forward-looking projects addressing systemic barriers to sustainable development.

Acknowledgments: This work has been partially funded by the University Politechnica of Bucharest, through "Excellence Research Grants" Program UPB-GEX 2017, DM59-17-01.

Author Contributions: Elena Fleacă conceived and designed the research, analyzed and interpreted data, and wrote the manuscript; Bogdan Fleacă contributed in the research design, execution of literature review, performed the experiment and analysis tool, and data interpretation; Sanda Maiduc contributed to the execution of literature reviewing, data interpretation, and experiment execution. All authors contributed to writing and completing the research paper, read and approved the final version of the manuscript.

Conflicts of Interest: The authors declare no conflict of interest.

\section{References}

1. United Nations Knowledge Platform. Transforming Our World: The 2030 Agenda for Sustainable Development. Available online: https:/ / sustainabledevelopment.un.org/content/documents/21252030\% 20Agenda\%20for\%20Sustainable\%20Development\%20web.pdf (accessed on 13 December 2017).

2. United Nations Knowledge Platform. Targets and Indicators. Available online: https:/ / sustainabledevelopment. un.org/sdg4 (accessed on 13 December 2017).

3. European Commission; Directorate-General for Employment, Social Affairs and Inclusion. Communication from the Commission to the European Parliament, the Council, the European Economic and Social Committee and the Committee of the Regions; A New Skills Agenda for Europe; Working Together to Strengthen Human Capital, Employability and Competitiveness; COM (2016) 381 Final; European Commission: Brussels, Belgium, 2016; pp. 13-16. Available online: http:/ / eur-lex.europa.eu/legal-content/EN/TXT/PDF/?uri=CELEX: 52016DC0381\&rid=6 (accessed on 13 December 2017). 
4. European Commission; Directorate-General for Education, Youth, Sport and Culture. Communication from the Commission to the European Parliament, the Council, the European Economic and Social Committee and the Committee of the Regions; On a Renewed EU Agenda for Higher Education; COM (2017) 247 Final; European Commission: Brussels, Belgium, 2017; pp. 4-12. Available online: http:/ / eur-lex.europa.eu/legal-content/EN/TXT/PDF/ ?uri=CELEX:52017DC0247\&rid=4 (accessed on 13 December 2017).

5. European Commission. Commission Staff Working Document on Implementing the UN Guiding Principles on Business and Human Rights—State of Play; SWD (2015) 144 Final; European Commission: Brussels, Belgium, 2015; pp. 1-60. Available online: https:/ / ec.europa.eu/anti-trafficking/sites/antitrafficking/files/swd_ 2015_144_f1_staff_working_paper_en_v2_p1_818385.pdf (accessed on 13 December 2017).

6. United Nations Knowledge Platform. Entrepreneurship for Development. A/71/210. 2016. Available online: https:/ / sustainabledevelopment.un.org/resources/documents (accessed on 13 December 2017).

7. European Commission. Communication from the Commission to the European Parliament, the Council, the European Economic Directorate-General for Migration and Home Affairs. and Social Committee and the Committee of the Regions; A Renewed EU Strategy 2011-14 for Corporate Social Responsibility; COM (2011) 681 Final; European Commission: Brussels, Belgium, 2011; Available online: http:/ / eur-lex.europa.eu/legal-content/ EN/TXT/PDF/?uri=CELEX:52011DC0681\&rid=1 (accessed on 15 December 2017).

8. European Commission. Europe 2020. A Strategy for Smart, Sustainable and Inclusive Growth; COM (2010) 2020 Final; European Commission: Brussels, Belgium, 2010; pp. 1-35. Available online: http:/ / eur-lex.europa.eu/ legal-content/EN/TXT/PDF/?uri=CELEX:52010DC2020\&rid=1 (accessed on 13 December 2017).

9. European Commission. Flash Eurobarometer 457-TNS Political \& Social. In Businesses' Attitudes towards Corruption in the EU; Directorate-General for Migration and Home Affairs: Brussels, Belgium, 2017.

10. European Commission. Special Eurobarometer 470-Wave EB88.2-TNS opinion \& social. In Corruption; Directorate-General for Migration and Home Affairs: Brussels, Belgium, 2017.

11. European Commission. Flash Eurobarometer 445-TNS Political \& Social. In The Cooperation and Verification Mechanism for Bulgaria and Romani-Third Wave; Directorate-General for Communication: Brussels, Belgium, 2017.

12. European Commission. Assessment of Progress on Structural Reforms, Prevention and Correction of Macroeconomic Imbalances, and Results of in-Depth Reviews under Regulation (EU) No 1176/2011; Commission Staff Working Document. Country Report Romania 2018; SWD (2018) 221 Final; European Commission: Brussels, Belgium, 2018; pp. 1-66. Available online: https://ec.europa.eu/info/sites/info/files/2018-european-semestercountry-report-romania-en.pdf (accessed on 15 December 2017).

13. European Commission. Report on Progress in Romania under the Cooperation and Verification Mechanism-COM (2017) 751 and SWD (2017) 701. Available online: https: / ec.europa.eu/info/effectivejustice/rule-law / assistance-bulgaria-and-romania-under-cvm/reports-progress-bulgaria-and-romania_ en (accessed on 15 December 2017).

14. Salvioni, D.M.; Gennari, F.; Bosetti, L. Sustainability and Convergence: The Future of Corporate Governance Systems? Sustainability 2016, 8, 1203. [CrossRef]

15. Sánchez-Hernández, M.I.; Gallardo-Vázquez, D.; Barcik, A.; Dziwiński, P. The Effect of the Internal Side of Social Responsibility on Firm Competitive Success in the Business Services Industry. Sustainability 2016, 8, 179. [CrossRef]

16. Ketschau, T.J. A Conceptual Framework for the Integration of Corporate Social Responsibility and Human Resource Development Based on Lifelong Learning. Sustainability 2017, 9, 1545. [CrossRef]

17. Radomska, J. The Concept of Sustainable Strategy Implementation. Sustainability 2015, 7, 15847-15856. [CrossRef]

18. Álvarez Pérez, C.; Rodríguez Montequín, V.; Ortega Fernández, F.; Villanueva Balsera, J. Integrating Analytic Hierarchy Process (AHP) and Balanced Scorecard (BSC) Framework for Sustainable Business in a Software Factory in the Financial Sector. Sustainability 2017, 9, 486. [CrossRef]

19. Pérez, C.Á.; Montequín, V.R.; Fernández, F.O.; Balsera, J.V. Integration of Balanced Scorecard (BSC), Strategy Map, and Fuzzy Analytic Hierarchy Process (FAHP) for a Sustainability Business Framework: A Case Study of a Spanish Software Factory in the Financial Sector. Sustainability 2017, 9, 527. [CrossRef]

20. International Organization for Standardization. Available online: https://www.iso.org/iso-26000-socialresponsibility.html (accessed on 15 December 2017). 
21. Global Reporting Initiative. Available online: https://www.globalreporting.org (accessed on 15 December 2017).

22. United Nations Global Compact. Available online: https://www.unglobalcompact.org/library/3101 and https: / sdgcompass.org/ (accessed on 15 December 2017).

23. International Organization for Standardization. Available online: https://www.iso.org/publication/ PUB100398.html (accessed on 15 December 2017).

24. United Nations Educational, Scientific and Cultural Organization (UNESCO). UNESCO Education Strategy 2014-2021; UNESCO Publishing: Paris, France, 2014.

25. United Nations Educational, Scientific and Cultural Organization (UNESCO). UNESCO Education for Sustainable Development Goals; UNESCO Publishing: Paris, France, 2017.

26. Ceulemans, K.; Lozano, R.; Alonso-Almeida, M.M. Sustainability Reporting in Higher Education: Interconnecting the Reporting Process and Organizational Change Management for Sustainability. Sustainability 2015, 7, 8881-8903. [CrossRef]

27. Moldovan, L. Sustainability Assessment Framework for VET Organizations. Sustainability 2015, 7, 7156-7174. [CrossRef]

28. Drăgan, M.; Ivana, D.; Arba, R. Business Process Modeling in Higher Education Institutions. Developing a Framework for Total Quality Management at Institutional Level. Proc. Econ. Financ. 2014, 16, 95-103. [CrossRef]

29. Fleacă, E. Core Processes Roadmap to Deploy the Higher Education Institution's Internationalization Strategy. TEM J. 2017, 6, 85-92. [CrossRef]

30. Fleacă, E.; Fleacă, B.; Maiduc, S. Modeling Stakeholders Relationships to Strengthen the Entrepreneurial Behavior of Higher Education Institutions. Proc. Eng. 2017, 181, 935-942. [CrossRef]

31. Harmon, P. Business Process Change: A Guide for Business Managers and BPM and Six Sigma Professionals, 2nd ed.; Morgan Kaufmann: Burlington, MA, USA, 2007; pp. 59-76.

32. Martins, P.V.; Zacarias, M. An Agile Business Process Improvement Methodology. Proc. Comput. Sci. 2017, 112, 129-136. [CrossRef]

33. Zacarias, M.; Martins, P.V.; Gonçalves, A. An Agile Business Process and Practice Meta-model. Proc. Comput. Sci. 2017, 112, 170-177. [CrossRef]

34. Gazova, A.; Papulova, Z.; Papula, J. The Application of Concepts and Methods Based on Process Approach to Increase Business Process Efficiency. Proc. Econ. Financ. 2016, 39, 197-205. [CrossRef]

35. Ariouat, H.; Hanachi, C.; Andonoff, E.; Benaben, F. A Conceptual Framework for Social Business Process Management. Proc. Comput. Sci. 2017, 112, 703-712. [CrossRef]

36. Rajnoha, R.; Sujová, A.; Dobrovič, J. Management and Economics of Business Processes Added Value. Proc. Soc. Behav. Sci. 2012, 62, 1292-1296. [CrossRef]

37. Pyzdek, T.; Keller, P. The Six Sigma Handbook, 4th ed.; McGraw-Hill: New York, NY, USA, 2014; pp. $271-291$.

38. Furterer, S. Lean Six Sigma in Service. Applications and Case Studies; Taylor \& Francis Group: Boca Raton, FL, USA, 2009; pp. 73-155.

39. Michael, L.G. Lean Six Sigma for Service. How to Use Lean Speed and Six Sigma Quality to Improve Services and Transactions; McGraw-Hill: New York, NY, USA, 2003; pp. 273-311.

40. American Productivity \& Quality Center. Available online: https://www.apqc.org/ (accessed on 6 January 2018).

41. Etzkowitz, H. Innovation in Innovation: The Triple Helix of University-Industry-Government Relations. Soc. Sci. Inf. 2003, 42, 293-338. [CrossRef]

(C) 2018 by the authors. Licensee MDPI, Basel, Switzerland. This article is an open access article distributed under the terms and conditions of the Creative Commons Attribution (CC BY) license (http://creativecommons.org/licenses/by/4.0/). 